\title{
Intensification of the Process Sorption Cleaning Oily Waste with the use Hydrothermodynamic Effects of Cavitation
}

\author{
Olga G. Dubrovskaya* and Vladimir A. Kulagin \\ Siberian Federal University \\ 79 Svobodny, Krasnoyarsk, 660041, Russia
}

Received 03.11.2015, received in revised form 15.12.2015, accepted 21.02.2016

The analysis of existing technological schemes of wastewater treatment oil and gas fields, evaluated the possibility of reuse of treated wastewater. The offered method of intensification of processes of purification, through the introduction of site hydro-thermodynamic cavitation installation with a subsequent sorption unit filters. The parameters and effectiveness of dynamic sorption in conditions of intensification of cavitational processing without the effects of cavitation. Studied the characteristics of sorbent "Unisorb-BI O". The optimal modes of operation of the sorption filters.

Keywords: wastewater treatment, oil products sorbents, sorption purification, reuse of wastewater, cavitation, hydrothermodynamic forcing.

\section{Интенсификация процессов сорбционной очистки нефтесодержащих сточных вод с использованием гидротермодинамических эффектов кавитации}

О.Г. Дубровская, В.А. Кулагин Сибирский федеральный университет Россия, 660041, Красноярск, Свободньй, 79

Проведен анализ существуюших технологических схем очистки сточных вод нефтегазовых месторождений, оценена возможность повторного использования очищенных сточных вод. Предложен способ интенсификации процессов очистки путем внедрения узла гидротермодинамической кавитаџионной установки с последующим блоком сорбиионных

\footnotetext{
(C) Siberian Federal University. All rights reserved

* Corresponding author E-mail address: dubrovskayaolga@mail.ru
} 
фильтров. Исследованы параметры и эффективность динамической сорбции в условиях интенсификачии кавитационной обработкой и без применения эффектов кавитации. Изучены характеристики сорбента «Унисорб-БИ О». Определены оптимальные режимы функционирования сорбциионных фильтров.

Ключевые слова: очистка сточных вод, сорбенты нефтепродуктов, сорбционная очистка, повторное использование сточных вод, кавитация, гидротермодинамическое воздействие.

\section{Введение}

Важность этой работы в общей постановке задач исследования обусловлена необходимостью совершенствования систем кондиционирования технических и сточных вод на базе новых наукоёмких технологий с целью повышения экономичности, надежности и безопасности существующих энергетических систем и комплексов. В то же время проблема, решаемая настоящим исследованием, является частью проблемы энергоресурсосбережения, или энергоэффективности производств, актуальной в силу известных факторов [1]:

- кризисного состояния российской экономики в целом и топливно-энергетического комплекса в частности;

- неоправданно высокого уровня удельных затрат энергии и других материальных ресурсов на единицу внутреннего валового продукта;

- объективной потребности в значительном реформировании российской экономики на базе научно обоснованной энергоресурсосберегающей политики.

Практически существуют два альтернативных пути ресурсной и, что не менее важно, экологической эффективности жизнедеятельности:

- реконструкция существующих технологических процессов на принципах построения малоотходных производств и безотходных комплексов;

- интенсификация производства полезного продукта при одновременном снижении потребления энергетических и материальных ресурсов в результате использования новых наукоемких технологий [1].

При непрерывном увеличении водопользования и загрязнения водоемов промышленными и бытовыми отходами острее становится проблема интенсификации очистки вод и сохранения гидросферы. В настоящее время кондиционирование сточных вод в большинстве своём осуществляется на морально и физически изношенном оборудовании с использованием традиционных технологий и методов механической и физико-химической обработки. С возрастанием водопотребления все большее значение приобретают задачи комплексного и рационального использования водных ресурсов, повышения качества и эффективности очистки и обеззараживания сточных вод, применения инновационного оборудования, современных материалов, технологий и механизмов $[2,3]$.

Одним из путей решения проблемы повышения эффективного водопользования является переход на оборотное водоснабжение $[4,5]$. Это возможно только при наличии локального очистного оборудования $[6,7]$. Лишь на единичных очистных сооружениях сток направляют на доочистку с использованием современных способов очистки и обеззараживания (озонирование, ультрафильтрация, обработка ультрафиолетовым излучением, электрохимическая обработка и др.) [8]. Каждый из перечисленных способов наряду с положительными сторонами

$$
-269-
$$


имеет и специфические недостатки, что заставляет искать новые пути развития экономически рациональных, ресурсо- и энергосберегающих методов и технологий очистки сточных вод.

Возникающие проблемы энергоресурсосбережения и экобезопасности в системах водоподготовки в энергетических комплексах могут быть решены с использованием эффектов кавитации [914]. Однако вопросы изменения физико-химических свойств воды (реологических, структурных и др.) и их влияния (на макроуровне) на ход и результат технологических процессов очистки промышленных стоков на современном этапе изучены недостаточно.

В этой связи возникает много вопросов, определяющих актуальность данной работы: о нахождении устойчивых режимов обработки воды, о влиянии кавитационного воздействия на физико-химические характеристики и релаксацию полученных свойств, о механизмах разрушения загрязнителей стоков при кавитационном воздействии, ответы на которые должны быть найдены в процессе всесторонних исследований.

Существующие технологии связаны с тремя основными процессами: катализом с интенсивным перемешиванием; диспергированием (механическим, химическим и биологическим); воздействием полей повышенных давлений и температур. От трети до половины всех энергетических затрат в различных технологиях идет на механическое диспергирование. Весьма сильную диспергацию дает химический способ - растворение. Наиболее распространенными растворителями являются вода и водные растворы щелочей и кислот. Перспективно применение активированной воды. Вода является либо дисперсной фазой, либо дисперсионной средой в большинстве технологических процессов [1].

В настоящее время фундаментальные и прикладные вопросы исследований кавитации в современных объектах техносферы являются приоритетными для обеспечения их безопасности. Гидродинамика кавитационных потоков, отличающаяся наличием парогазовых включений (отдельных пузырей, пузырьковых кластеров и облаков, суперкавитационных полостей) имеет ряд особенностей, существенно затрудняющих ее изучение, моделирование и в конечном итоге управление.

Современное состояние развивающихся методов численного моделирования кавитационных процессов не позволяет в ряде случаев обеспечить приемлемый уровень их описания даже при использовании наиболее современных моделей и суперкомпьютерных мощностей. Это связано с чрезвычайной сложностью, многомасштабностью и многообразием физических процессов, протекающих при кавитации.

Использование гидродинамических и теплофизических эффектов кавитации (кавитационной технологии) [1] способствует механотермолизу структуры воды с появлением свободных водородных связей, диспергации и гомогенизации с образованием устойчивых эмульсий, суспензий и смесей, имеющим перспективу для усовершенствования и интенсификации технологических процессов в различных отраслях производства. В области изменения свойств воды установлено, что в результате гидродинамической обработки ее физические характеристики существенно изменяются и сохраняются достаточно длительное время (до 7-10 суток), что позволяет использовать модифицированную воду в различных технологических процессах.

Наблюдается быстрое кислородонасыщение в воздушной среде, объясняемое наличием кроме диффузионного (за счет высокой степени сжатия парогазового содержимого кавитаци- 
онного микропузырька), также кинетического механизма насыщения воды кислородом, приводящего к ощутимой неравновесности процесса его растворения.

При непрерывном увеличении водопотребления и загрязнения водоемов промышленными и бытовыми отходами острее ставится проблема интенсификации очистки вод и сохранения гидросферы. Это связано с тем, что возрастание объёмов сточных вод влечет за собой необходимость увеличения площадей, занимаемых очистными сооружениями, что не всегда возможно в условиях урбанизированных территорий. Поэтому перед предприятиями и городскими службами стоит задача использования инновационного оборудования, с использованием современных материалов, технологий и оборудования. Проведенные ранее исследования по применению кавитационной технологии в различных процессах показали ряд положительных результатов [15-22].

Например, одной из основных проблем низкой эффективности применяемых на автомоечных станциях очистных комплексов является неправильный подбор технологической схемы очистки сточных (оборотных) вод [7]. При проектировании или монтаже готовой очистной системы необходимо учитывать не только мощность, производительность станции, качественные и количественные показатели загрязненности стока, но и систему обеззараживания повторно используемой воды в оборотном водоснабжении.

Сточная вода, поступающая в оборотную систему водоочистки, содержит большое количество нефтепродуктов, поверхностно-активных веществ, взвесей. Для приведения стока к нормативным показателям оборотного водоснабжения автомоечного комплекса используются традиционные методы механической и физико-химической обработки стока [23-30]. От эффективности работы очистного оборудования в значительной мере зависит объем и качество работы автомоечной станции, расходы сырья и энергии. При подборе существующей технологической схемы не учитывается биозагрязнение. Между тем эффективность работы систем оборотного водоснабжения значительно снижается в процессе эксплуатации вследствие образования различного рода отложений и обрастаний в теплообменных аппаратах, в трубопроводах и резервуарах чистой воды (РЧВ). Помимо этого ряд случаев отказа оборудования обусловлен образованием биопленки [5] и веществ, выделяемых в процессе метаболизма обрастателей. Микроорганизмы, прикрепившиеся к стенкам трубопроводов, образуют достаточно толстый слой, обладающий высокой прочностью на разрыв, вследствие чего увеличивается площадь твердой поверхности, создаваемой самими обрастателями. Это приводит к тому, что последующие клетки могут оседать и прикрепляться к ранее поселившимся клеткам. Таким образом, на поверхности появляются обрастатели второго, третьего и более высоких порядков. Прогрессирующая колонизация поверхности формирует на ней сообщества со сложной многоярусной структурой, вследствие чего возрастает пространственная гетерогенность и, соответственно, число потенциальных экологических ниш. Негативное влияние биообрастаний достаточно полно рассмотрено в $[5,11,31]$.

Актуальность исследований, направленных на решение вопроса компоновки технологической схемы и подбора оборудования для очистки сточных вод нефтегазовых месторождений, обусловлена необходимостью повторного использования очищенных стоков для поддержания пластового давления при разработке нефтяных и газовых скважин. 
Требуемые объемы возвратных пластовых вод достаточно велики. Ориентировочный расход воды для добычи одной тонны нефти составляет в среднем 1,6-2,5 м³ - при законтурном заводнении и 10-15 м³ - при площадном заводнении.

Воды, закачиваемые в пласт, требуют особой подготовки, а так как на 40-50 \% это сточные воды различного происхождения, то необходимо разработать технологическую схему очистки с высокой эффективностью удаления таких полютантов, как нефтепродукты, взвешенные вещества, железо общее, соли кальция, магния, калия (карбонаты, гидрокарбонаты сульфаты), микроорганизмы [8].

Частицы водорослей, ила, соединения железа, содержащиеся в нагнетаемой воде, соли жесткости закупоривают поровые каналы продуктивного пласта, снижая приемистость нагнетательных скважин. Присутствующие же в закачиваемой воде микроорганизмы могут образовать нежелательные соединения. Так, сульфатвосстанавливающие бактерии в процессе жизнедеятельности вырабатывают сероводород в количестве до 100 мг/л. В последующем этот коррозионно-активный газ подвергает разрушению трубопроводы, аппараты и оборудование. Кроме того, данные бактерии провоцируют выделение карбоната кальция и сульфида железа, которые, в свою очередь, образуют минеральные отложения в трубопроводах, сооружениях, оборудовании.

Согласно ОСТ 39-225-88 «Вода для заводнения нефтяных пластов. Требования к качеству» вода, предназначенная для закачки в пласты, должна содержать не более 2 мг/л взвешенных твердых частиц с крупностью 15 мкм, 0,3 мг/л железа, 0,5 мг/л нефтепродуктов с крупностью эмульгированных частиц не более 5 мкм, 0,05 мг/л растворенного кислорода.

Существующие технологические схемы подготовки сточных вод, закачиваемых в пласт, предусматривают:

1) осветление мутных вод коагулированием;

2) декарбонизацию;

3) обезжелезивание;

4) ингибирование.

Для подготовки сточных вод на нефтегазовых месторождениях используют схемы открытого и закрытого типа.

\section{Техника эксперимента}

Принципиальная схема установки очистки пластовых сточных вод открытого типа приведена на рис. 1. Отделенная при подготовке нефти вода сбрасывается по водоводу в песколовку 1 для удаления механических примесей. Далее вода, содержащая нефть, поступает в нефтеловушку 2, где за счет низкой скорости движения смеси капельки нефти успевают всплыть и откуда она периодически откачивается насосом 3 на установку комплексной подготовки нефти (УКПН). Далее вода с остаточным содержанием нефти (диаметр капель 70...80 мкм) самотеком поступает в два параллельно соединенных отстойника 4, в которых скорость воды не превышает 8 мм/с, в результате чего в ней всплывают практически все оставшиеся капельки нефти. Из отстойников вода самотеком поступает в приемную камеру 5 , из которой забирается насосом 6 и через попеременно работающие фильтры 7 подается в емкость очищенной воды 8. Затем эта вода насосом 9 откачивается на канализационную насосную станцию (КНС). По мере загряз- 


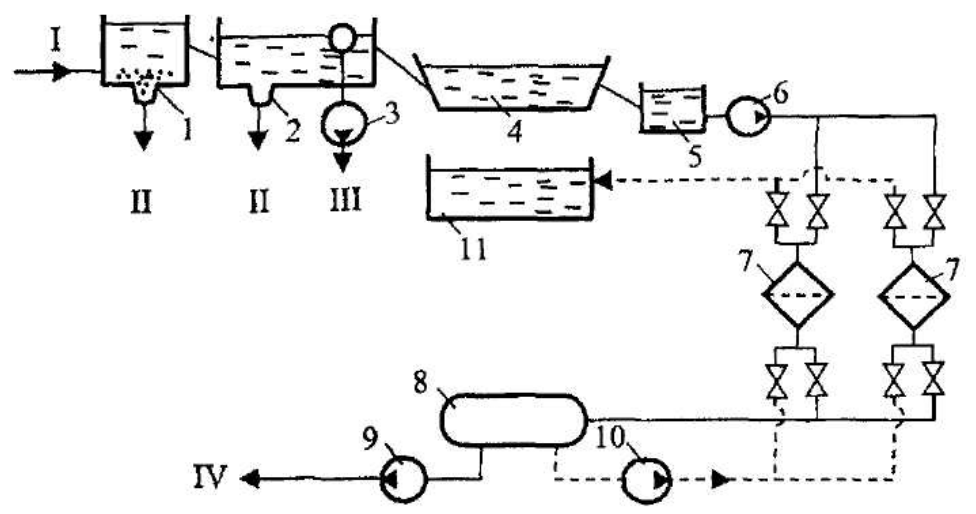

Рис. 1. Схема установки очистки пластовых вод открытого типа: 1 - песколовка; 2 - нефтеловушка; 3 , 6, 9, 10 - насосы; 4 - пруд-отстойник; 5 - приёмная камера; 7 - фильтр; 8 - емкость чистой воды; 11 накопитель; I - загрязнённая вода; II - мехпримеси; III - нефть на УКПН; IV - вода на КНС

нения фильтры отключают и ставят на промывку чистой водой из емкости 8 с помощью насоса 10. Загрязненную после промывки воду сбрасывают в накопитель 11.

Схема водоподготовки открытого типа позволяет очищать технические и ливневые сточные воды в одном потоке независимо от состава, давления и газонасыщенности воды, а также совместно закачивать их в нагнетательные скважины. Обычно ее рекомендуют использовать для сточных вод с большим содержанием сероводорода и углекислого газа. Однако эффективность очистки стока по данной схеме не превышает 60 \%, а экономические затраты на ее компоновку и эксплуатацию достаточно велики. Кроме того, в результате контакта с кислородом воздуха увеличивается коррозионная активность воды.

Принципиальная схема установки очистки пластовых сточных вод закрытого типа приведена на рис. 2. Отделенная от нефти в отстойнике предварительного сброса (ОПС) вода по линии сброса 1 направляется в резервуар-отстойник 2, частично обезвоженная нефть (до 5 \%), пройдя УКПН, поступает в теплоизолированные отстойники 3. Процесс отделения воды в них ускоряется благодаря произведенному в УКПН нагреву и вводу поверхностно-активных веществ. Отделенная горячая вода поступает на прием насоса 4 и снова подается в отстойник предварительного сброса УКПН, что позволяет уменьшить расход деэмульгатора и температуру нагрева эмульсии. Из резервуара-отстойника 2 пластовая сточная вода забирается насосом 5 и подается на КНС.

Применение закрытой системы очистки позволяет интенсифицировать процесс подготовки воды с применением отстаивания и фильтрования под давлением, существенно снизить агрессивность сточной воды путем исключения ее контакта с кислородом воздуха, использовать остаточное давление, существующее в системе подготовки нефти $[2,32]$. К недостаткам закрытых систем относится необходимость строительства блока для параллельной очистки поверхностных ливневых стоков.

Для интенсификации работы замкнутых систем очистки стока перед стадией фильтрования предлагается включить блок кавитационной обработки, например, построенных на конструкционных особенностях оборудования, описанных в $[33,34]$ с последующей доочисткой на сорбционных сооружениях. Данный метод позволяет достичь высокого степени очистки

$$
-273-
$$




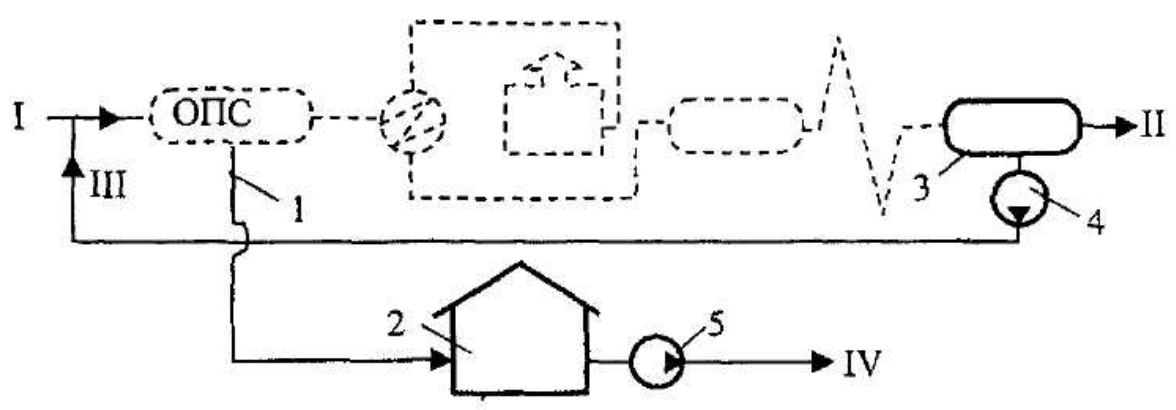

Рис. 2. Схема установки очистки пластовых сточных вод закрытого типа: 1 - линия сброса воды из отстойника; 2 - резервуар-отстойник; 3 - теплоизолированный отстойник; 4, 5 - насосы; I - холодная «сырая» нефть; II - обезвоженная нефть; III - горячая вода с ПАВ; IV - очищенная вода на КНС

при значительном сокращении времени фильтрования, интенсифицировать процессы сорбции за счет гомогенизации смеси и ее нагрева в кавитационном реакторе, кроме эффектов, перечисленных выше [1]. Получаемые в результате цепной перекомбинации атомов водорода и кислорода продукты реакций - перекись водорода, озон, атомарный кислород - окисляют углеполимеры, входящие в состав нефтепродуктов до димономеров $[4,6]$, что в значительной степени ускоряет процесс сорбции, повышает степень извлечения нефтепродуктов из стока и в значительной мере снижает десорбционные явления. Очищенная сточная вода соответствует по физико-химическим и микробиологическим показателям технической воде для повторного использования как в виде возвратной пластовой, так и в виде производственно-технической.

\section{Обсуждение результатов экспериментов}

Среди методов, связанных с удалением загрязнений из сточных вод различного назначения, сорбционная очистка является одним из наиболее эффективных способов. Многие авторы обосновывают возможность использования отходов природных и синтетических полимерных материалов в качестве сорбентов для очистки сточных вод от нефти и нефтепродуктов. Ряд нефтеемких сорбентов может быть создан на базе технических остатков производства ваты, низкосортной технической ваты, отходов текстильного производств [32, 35]. В качестве активной загрузки в данном исследовании выбран сорбент «Унисорб-БИО». Основные характеристики данного сорбента даны в табл. 1. Сорбент, выбранный в качестве активной загрузки, представляет особый интерес с точки зрения компоновки минеральных комплексов и нефтеокисляющих культур микроорганизмов, закрепленных в порах препаратов. Одним из главных преимуществ исследуемого сорбента является то, что он не просто аккумулирует в себе нефтепродукты как другие сорбенты, а подвергает их разложению под воздействием иммобилизованной микрофлоры. Данный сорбент относится к классу биосорбентов. Гранулы биосорбентов имеют микропористую, мезопористую и слоистую чешуйчатую макропористую структуру, поверхность покрыта гидрофобной углеродной пленкой. Исследуемый сорбент «Унисорб-БИО» негорюч, невзрывоопасен, с длительным эксплуатационным сроком (до 3 лет), биорегенерируемый, утилизируемый по IV классу опасности. С целью выявления наиболее эффективного кавитационного режима обработки сточной воды и определения оптимальных режимов работы сорбционной установки проведены экспериментальные исследования и оценен результат по 
Таблица 1. Характеристика сорбента

\begin{tabular}{|c|c|}
\hline Показатель, единицы измерения & Унисорб-БИО \\
\hline Насыпная плотность, кг/м³ & $18-25$ \\
\hline Размер хлопьев (крошки), мм & $3-10$ \\
\hline Сорбционная емкость по нефти, кг нефти / кг препарата & $30 / 60$ \\
\hline Снижение межфазного натяжения (вода - нефть), эрг/ см² & $2,5-3,5$ \\
\hline \multicolumn{2}{|l|}{ Доля переработанной микроорганизмами нефти после 7 - 14 сут: } \\
\hline \multicolumn{2}{|l|}{ а) биодеструктивная активность в аэробных условиях, \% } \\
\hline при более $10^{\circ} \mathrm{C}$ & $50-70$ \\
\hline при $0 \ldots 10^{\circ} \mathrm{C}$ & $25-40$ \\
\hline \multicolumn{2}{|l|}{ б) биодеструктивная активность в анаэробных условиях, \% } \\
\hline при более $10^{\circ} \mathrm{C}$ & $20-35$ \\
\hline при $0 \ldots 10^{\circ} \mathrm{C}$ & $10-15$ \\
\hline Уменьшение активности после трех лет хранения, \% & $30-40$ \\
\hline
\end{tabular}

Таблица 2. Результаты эксперимента

\begin{tabular}{|c|c|c|c|c|c|}
\hline 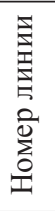 & $\begin{array}{c}\text { Исходная } \\
\text { концентрация } \\
\text { нефтепродуктов } \\
\text { в модельной воде, } \\
\text { мг/л }\end{array}$ & $\begin{array}{l}\text { Условия } \\
\text { сорбции }\end{array}$ & $\begin{array}{c}\text { Режим } \\
\text { кавитационной } \\
\text { обработки } \\
\text { (скорость вращения } \\
\text { кавитатора, время } \\
\text { воздействия) }\end{array}$ & $\begin{array}{c}\text { Конечная } \\
\text { концентрация } \\
\text { (интенсифицированная } \\
\text { сорбция/сорбция без } \\
\text { интенсификации), мг/л }\end{array}$ & $\begin{array}{c}\text { Эффект очистки, \% } \\
\text { (интенсифицированная } \\
\text { сорбция/сорбция без } \\
\text { интенсификации) }\end{array}$ \\
\hline 1 & 10 & \multirow{3}{*}{$\begin{array}{c}\text { Нормальные } \\
\text { условия } \\
\left(20 \pm 2{ }^{\circ} \mathrm{C}\right)\end{array}$} & \multirow{3}{*}{$\begin{array}{c}9000 \text { об/мин, } \\
90 \text { с }\end{array}$} & $0,12 / 1,9$ & 98,8 / 81 \\
\hline 2 & 15 & & & $0,08 / 3,27$ & $99,5 / 78,2$ \\
\hline 3 & 20 & & & $0,08 / 4,34$ & $99,6 / 78,3$ \\
\hline 4 & 10 & \multirow{3}{*}{$\begin{array}{c}\text { Нагрев } \\
\text { до } 40 \pm 2^{\circ} \mathrm{C}\end{array}$} & \multirow{3}{*}{$\begin{array}{c}5000 \text { об/мин, } \\
60 \mathrm{c}\end{array}$} & $0,06 / 1,4$ & $99,4 / 86$ \\
\hline 5 & 15 & & & $0,09 / 2,2$ & $99,4 / 85,3$ \\
\hline 6 & 20 & & & $0,28 / 3,84$ & $98,6 / 80,8$ \\
\hline 7 & 10 & $\begin{array}{c}\text { Охлаждение } \\
\text { до } 0,14^{\circ} \mathrm{C}\end{array}$ & $\begin{array}{c}9000 \text { об/мин, } \\
90 \text { с }\end{array}$ & $2,3 / 8,75$ & $77 / 12,45$ \\
\hline
\end{tabular}

остаточному содержанию нефтепродуктов с применением ИК-спектрометрии в соответствии с ГОСТ Р 51797-2001, ПНДФ 14.1:2:4.168-2000, ФР.1.31.2008.04409, МУК 4.1.1013-01.

В ходе исследований было проведено 7 линий эксперимента с модельной и натурной водой, имеющей разную исходную концентрацию нефтепродуктов (от 10-20 мг/л). Выбран режим динамической сорбции при различных температурах и разных режимах гидротермодинамического воздействия. В ходе эксперимента отслеживалась концентрация эмульгированных нефтепродуктов инфильтратов (табл. 2).

Таким образом, по результатам экспериментального исследования можно сделать вывод о том, что оптимальный режим динамической сорбции с условием интенсификации гидротермодинамической обработки сточной нефтесодержащей воды определен именно параметрами работы кавитационной установки с числом вращения ротора 9000 об/мин и временем обработ- 


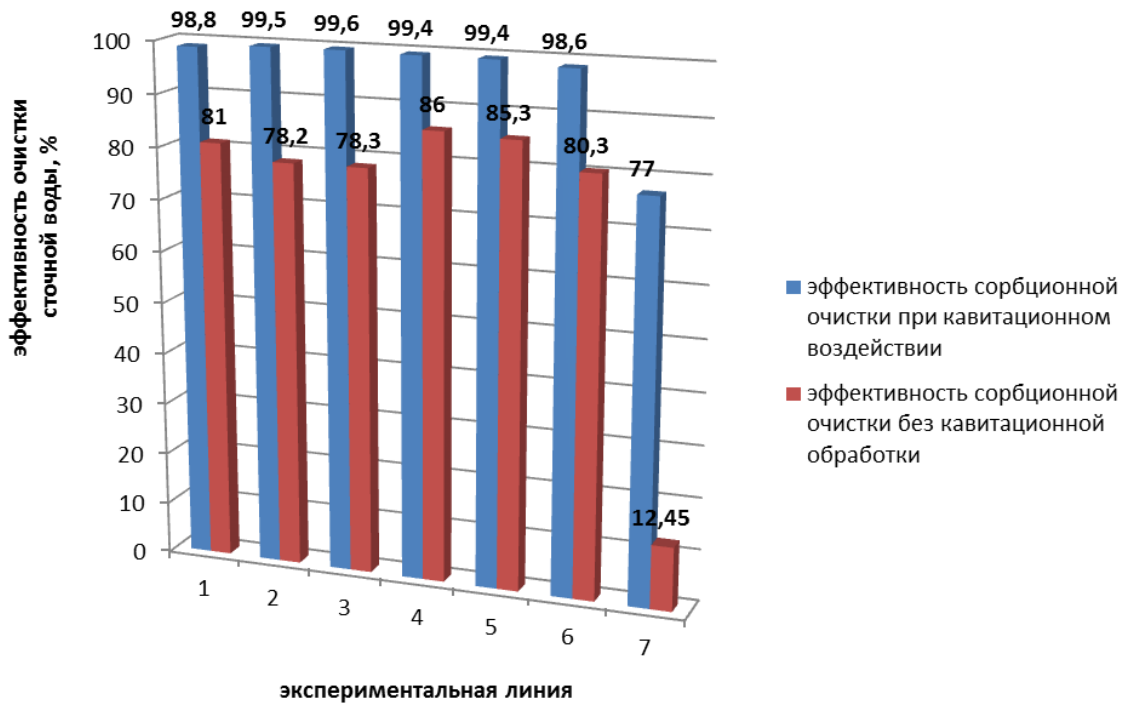

Рис. 3. Эффективность сорбционной очистки нефтесодержащих сточных вод при различных режимах динамической сорбции

ки 90 с. При этом важным выводом является то, что температурные характеристики сточной жидкости практически не снижают эффект сорбционной очистки при кавитационной активации, тогда как исследуемый сорбент без интенсификации показывает низкую эффективность, при повышении температуры стока показатели эффективности значительно ухудшаются, а при экстремальном понижении температуры сорбент становится неприемлемым (рис. 3).

\section{Выводы}

Результаты исследования свидетельствуют о целесообразности введения узла кавитационной обработки сточной нефтесодержащей воды перед блоком сорбционных фильтров, целью интенсификации процесса динамической сорбции и повышения эффективности очистки с последующей компоновкой оборотной системы водопользования при подготовке пластовой и технической воды в закрытых циклах.

\section{Список литературы}

[1] Кулагин В.А. Методы и средства технологической обработки многокомпонентных сред с использованием эффектов кавитации. Дис. ... Д-ра техн. наук, Красноярск: КГТУ, 2004, 379 c. [Kulagin V.A. Methods and means of processing multi- media using cavitation effects. Dis .... Dr. tehn . sciences, Krasnoyarsk : KGTU, 2004, 379 p. (in Russian) ]

[2] Когановский А.М., Клименко Н.А., Левченко Т.М. и др. Очистка и использование сточных вод в промышленном водоснабжении. М.: Химия, 1983, 288 с. [Koganovsky A.M., Klimenko N.A., Levchenko T.M. Treatment and use of wastewater in industrial water supply. M .: Chemistry, 1983, 288 p. (in Russian)]

[3] Евстигнеев В.В., Кулагин В.А. Гидротермодинамическая технология обработки сточных вод. Вестник МАНЕБ, 2009, 14(6), 242-245 [Evstigneev V.V., Kulagin V. A. Hydro-

$$
-276-
$$


thermodynamic technology of wastewater treatment . MANEB Bulletin 2009, 14 (6) 242- 245 (in Russian)]

[4] Дубровская О.Г., Евстигнеев В.В., Кулагин В.А. Проблемы очистки сточных вод, содержащих эмульгированные нефтепродукты в оборотных системах замкнутых циклов водопользования, и пути их решения. Журнал СФУ. Техника и технологии, 2013, 6(6), 680-688 [Dubrovskaya O.G., Evstigneev V.V., Kulagin V.A. Problems of wastewater containing emulsified oil in the circulating water systems, closed cycles and their solutions, J. Sib. Fed. Univ. Eng. technol., 2013, 6(6), 680 - 688 (in Russian)]

[5] Дубровская О.Г., Евстигнеев В.В., Кулагин В.А. Проблемы биообрастания в оборотных системах замкнутых циклов водопользования и пути их решения. Безопасность жизнедеятельности, 2012, 3, 26-30. [Dubrovskaya O.G., Evstigneev V.V., Kulagin V.A. The problem of biofouling in the circulating closed loop water usage and ways to solve their, J. Health and Safety., 2012, 3, 26 - 30 (in Russian)]

[6] Дубровская О.Г., Евстигнеев В.В., Кулагин В.А. Кондиционирование сточных вод энергетических систем и комплексов. Журнал СФУ. Техника и технологии, 2011, 4(6), 629-641. [Dubrovskaya O.G., Evstigneev V.V., Kulagin V.A. Conditioning of waste water of energy systems, J. Sib. Fed. Univ. Eng. technol., 2011, 4(6), 629 - 641 (in Russian)]

[7] Дубровская О.Г., Кулагин В.А., Сапожникова Е.С. Современные компоновки технологических схем очистки сточных вод с использованием кавитационной технологии. Журнал СФУ. Техника и технологии, 2015 8(2), 217-223. [Dubrovskaya O.G., Kulagin V.A., Sapoghnikova E.S. Modern Variants of Technological Schemes for Sewage Purification with the Use of Impulse Cavitation Technology, J. Sib. Fed. Univ. Eng. technol., 2015, 8(2), 217 - 223 (in Russian)]

[8] Дубровская О.Г., Андруняк И.В., Приймак Л.В. Ресурсосберегающие технологии обезвреживания и утилизачии отходов предприятий теплоэнергетического комплекса Красноярского края, Монография. Красноярск: Сиб. федер. ун-т, 2014, 164 с. [Dubrovskaya O.G., Andrunyak I.V., Priymak L.V. Resource-saving technologies of waste disposal and recycling enterprises thermal power complex of the Krasnoyarsk Territory, Monograph. Krasnoyarsk : Sib . Feder . University Press, 2014, 164p. (in Russian)]

[9] Кулагин В.А. Суперкавитация в энергетике и гидротехнике. Монография. Красноярск: ИПЦ КГТУ, 2000, 107 с. [Kulagin V.A. Supercavitation energy and hydraulic engineering . Monograph. Krasnoyarsk : IPC KGTU, 2000, 107 p. (in Russian)]

[10] Кулагин В.А., Вильченко А.П., Кулагина Т.А. Моделирование двухфазных суперкавитационных потоков. Монография. Красноярск: ИПЦ КГТУ, 2001, 187 с. [Kulagin V.A., Vilchenko A.P., Kulagina T.A. Simulation of two-phase flows supercavitation . Monograph. Krasnoyarsk : IPC KGTU, 2001, 187 p. (in Russian)]

[11] Евстигнеев В.В., Кулагин В.А. Кавитация в технологиях очистки сточных вод, $B$ мире научных открытий, 2010, 5-1, 87-90 [Evstigneev V.V., Kulagin V.A. Cavitation in wastewater treatment technology, In the World of Scientific Discovery, 2010, 5-1, 87-90 (in Russian)]

[12] Демиденко Н.Д., Кулагин В.А., Шокин Ю.И., Ли Ф.-Ч. Тепломассообмен и суперкавитация. Новосибирск: Наука, 2015, 436 с. [Demidenko N.D., Kulagin V.A., Shokin Y.I., Lee F.-Ch. Heat and Mass Transfer and supercavitation . Novosibirsk, Nauka. 2015, 436 p. (in Russian)]

$$
-277-
$$


[13] Демиденко Н.Д., Кулагин В.А., Шокин Ю.И. Моделирование и вычислительные технологии распределенных систем, Новосибирск: Наука, 2012, 424 с. [Demidenko N.D., Kulagin V.A., Shokin Y.I. Modeling and computational technology distributed systems. Novosibirsk, Nauka. 2012, 436 p. (in Russian)]

[14] Kulagin, V. A.; Kulagina, T. A.; Kulagina, L. V. Nanotechnology Cavitational Effects in the Heat-and-Power Engineering and Other Branches of Production, J. Sib. Fed. Univ. Eng. technol. 2008 1(1), 76-85.

[15] Кулагин В.А., Пьяных Т.А. Исследование кавитационных течений средствами математического моделирования. Журнал СФУ. Техника и технологии, 2012 5(1), 57-62. [ Kulagin V.A., Pyanykh T.A. Research of Cavitating Flows by Methods of Mathematical Simulation, J. Sib. Fed. Univ. Eng. technol., 2012, 5(1), 57 - 62 (in Russian)]

[16] Кулагин В.А., Пьяных Т.А. Определение расчетных зависимостей рабочих параметров суперкавитационного испарителя. Журнал СФУ. Техника и технологии, 2013, 6(1), 44-49. [Kulagin V.A., Pyanykh T.A. Definition Calculated Dependencies Performance Supercavitating Evaporator, J. Sib. Fed. Univ. Eng. technol., 2013, 6(1), 44 - 49 (in Russian)]

[17] Кулагин В.А., Пьяных Т.А. Моделирование процессов в суперкавитационном испарителе с учетом термодинамических эффектов. Химическое и нефтегазовое машиностроение, 2014, 1, 18-20 [Kulagin V.A., Pyanykh T.A. Modeling of processes in supercavitation evaporator considering thermodynamic effects. Chemical and Petroleum Engineering, 2014, 1, 18-20 (in Russian)]

[18] Zheng Z Y, Qian Li, Feng-Chen Li, Vladimir A. Kulagin Numerical study on the characteristics of natural supercavitation by planar symmetric wedgeshaped cavitators for rotational supercavitating evaporator, Sci China Tech Sci, 2015, 58: 1-12, doi: 10.1007/s11431-015-5827-y

[19] Zheng Zhiying, Li Qian, Li Fengchen, Vladimir A. Kulagin, Numerical study on parameter selection for steam extraction of rotational supercavitating evaporator, Journal of University of Chinese Academy of Sciences, 2015.

[20] Likhachev D.S., Li F-C, Kulagin V.A. Experimental study on the performance of a rotational supercavitating evaporator for desalination, Sci. China. Tech. Sci., 2014, 57: 2115-2130, doi: 10.1007/ s11431-014-5631-0

[21] Kulagin V.A., Pyanykh T.A. Modeling of processes in supercavitation evaporator with consideration of thermodynamic effects, Chemical and Petroleum Engineering. Nos. 1-2, May. 2014. Vol. 50. 24-29. DOI 10.1007/s10556-014-9848-3

[22] Кулагин В.А., Пьяных Т.А. Расчет режимных параметров суперкавитационного испарителя. Международный научно-исследовательский журнал, 2013, 8(15), 56-59. Ч. 2. http:// research-journal.org/wp-content/uploads/2011/10/8-2-15_d.pdf [Kulagin V.A., P,yanykh T.A. Calculation of operational parameters of supercavitation evaporator. Meždunarodnyj naučno-issledovatel'skij žurnal, 2013, 8(15), 56- 59. Ч. 2. http://research-journal.org/wp-content/uploads/2011/10/8-2-15_d.pdf (in Russian)]

[23] Колесников В.А., Меньшутина Н.В. Анализ, проектирование технологий и оборудования для очистки сточных вод. М.: ДеЛи принт, 2005, 266 c.[ Kolesnikov V.A., Menshutina N.V. Analysis, design technology and equipment for wastewater treatment . M .: DeLi print, 2005, $266 \mathrm{p}$. (in Russian)] 
[24] Кульский Л.А., Строкач П.П. Технология очистки природных вод. 2-е изд., перераб. и доп. Киев: Вища шк. 1986, 352 с.[ Kulskiy L.A., Strokach P.P. The technology of water purification . 2th ed, revised. and ext. Kiev: Vishcha sch . 1986, 352 p. (in Russian)]

[25] Кульский Л.А. Теоретические основы и технология кондичионирования воды: 4-е изд. перераб. и доп. Киев: Наукова думка, 1983, 528 с.[ Kulskiy L.A. Theoretical Foundations and water conditioning technology: 4th ed . revised. and ext. Naukova Dumka, 1983, 528 p. (in Russian)]

[26] Кульский Л.А., Сиренко Л.А., Шкавро З.Н. Фитопланктон и вода. Киев: Наукова думка, 1986, 133 c.[ Kulskiy L.A., Sirenko L.A., Shkavro Z.N. Phytoplankton and water . Naukova Dumka, 1986, 133 p. (in Russian)]

[27] Рябов А.К., Сиренко Л.А. Искусственная аэраџия природных вод, Киев: Наукова думка, 1982, 204 с.[ Ryabov A.K., Sirenko L.A. Artificial aeration of natural waters, Naukova Dumka, 1982, 204 p. (in Russian)]

[28] Тебенихин Е.Ф., Горяинов Л.А. Обработка воды для теплоэнергетических установок железнодорожного транспорта. М.: Транспорт, 1986,160 с. [ Tebenihin E.F., Goryainov L.A. Water treatment plants for heat and power rail. M .: Transport, 1986.160 p. (in Russian)]

[29] Тебенихин Е.Ф., Гусев Б.Т. Обработка воды магнитным полем в теплоэнергетике. М.: Энергия, 1970, 143 c.[Tebenihin E.F., Gusev B.T. Water treatment by a magnetic field in the heat . M $\therefore$ Energia, 1970, 143 p. (in Russian)]

[30] Торочешников Н.С., Родионов А.И., Кельцев Н.В., Клушин В.Н. Техника защиты окружающей среды. М.: Химия, 1981, 368 с.[ Torocheshnikov N.S., Rodionov A.I., Kelcev N.V., Klushin V.N. Technology to protect the environment. M .: Chemistry, 1981, 368 p (in Russian)]

[31] Дубровская О.Г. Технология гидротермодинамической обработки природных и сточных вод с использованием эффектов кавитации. Автореф. дис. ... канд. техн. наук: 01.14.04, 05.23.04 . Сибирский федеральный университет; рук. работы В. А. Кулагин. Красноярск, 2007, 22 c. [Dubrovskaya O.G. Technology hydrothermodynamic treatment of natural and waste water using the cavitation effects. Author. Dis. ... cand . tehn . sciences 01.14.04, 05.23.04 Sib . Feder . University, the work head V.A. Kulagin. Krasnoyarsk, 2007, 22 p. (in Russian)]

[32] Собгайда Н.А., Ольшанская Л.Н., Макарова Ю.А. Фильтры из отходов для очистки сточных вод. Экология производства, 2012, 3, 40-41.[ Sobgayda N.A., Ol'shanskaya L.N. Makarova Y.A. Filters from the waste effluent treatment . Ecology of production, 2012, 3, 40-41. (in Russian)]

[33] Кулагин В.А. Суперкавитационный миксер. Гидродинамика больших скоростей. Красноярск: КрПИ, 1992, 134-140.[ Kulagin VA Supercavitation mixer. Hydrodynamics of high speeds . Krasnoyarsk : KrPI, 1992, 134-140. (in Russian)]

[34] А. с. 1755906 СССР, МКИ В01F5/00. Кавитационный смеситель, В.А. Кулагин, Т.А. Кулагина, Е.П. Грищенко (СССР). № 4760709/26; заявл. 07.08.89; опубл. 23.08.92, Бюл. № 31. 4 с.[ А. p. 1755906 USSR MKI B01F5 / 00 . Cavitation mixer, V.A. Kulagin, T.A. Kulagina, E.P. Grishchenko (USSR ) . № 4760709/26; appl . 07/08/89 ; publ. 23.08.92, Bul. № 31. 4(in Russian)]

[35] Стрепетов И.В., Москвичева Е.В. Использование сорбентов на основе отходов полимерных материалов для очистки сточных вод от нефтяных загрязнений. Строительство и архитектура, 2010. [Strepetov I.V., Moskvicheva E.V. The use of sorbents based on polymer waste materials for wastewater from oil pollution . Construction and architecture 2010 . (in Russian)]

$$
-279 \text { - }
$$

